\section{A) Check for updates}

Cite this: Nanoscale, 2020, 12, 5412

\title{
Spin transition nanoparticles made electrochemically $\dagger$
}

\author{
Guillermo Pozo, ${ }^{a}$ Patricia de la Presa, ${ }^{\mathrm{b}, \mathrm{c}}$ Rafael Prato, ${ }^{\mathrm{a}, \mathrm{d}}$ Irene Morales, ${ }^{\mathrm{b}, \mathrm{c}}$ \\ Pilar Marin, ${ }^{b, c}$ Jan Fransaer ${ }^{d}$ and Xochitl Dominguez-Benetton (D) $*^{a}, e$
}

\begin{abstract}
Materials displaying novel magnetic ground states signify the most exciting prospects for nanoscopic devices for nanoelectronics and spintronics. Spin transition materials, e.g., spin liquids and spin glasses, are at the forefront of this pursuit; but the few synthesis routes available do not produce them at the nanoscale. Thus, it remains an open question if and how their spin transition nature persists at such small dimensions. Here we demonstrate a new route to synthesize nanoparticles of spin transition materials, gas-diffusion electrocrystallization (GDEx), wherein the reactive precipitation of soluble metal ions with the products of the oxygen reduction reaction (ORR), i.e., in situ produced $\mathrm{H}_{2} \mathrm{O}_{2}, \mathrm{OH}^{-}$, drives their formation at the electrochemical interface. Using mixtures of $\mathrm{Cu}^{2+}$ and $\mathrm{Zn}^{2+}$ as the metal precursors, we form spin transition materials of the herbertsmithite family-heralded as the first experimental material known to exhibit the properties of a quantum spin liquid (QSL). Single-crystal nanoparticles of $\sim 10-16 \mathrm{~nm}$ were produced by GDEx, with variable $\mathrm{Cu} / \mathrm{Zn}$ stoichiometry at the interlayer sites of $\mathrm{Zn}_{x} \mathrm{Cu}_{4-x}(\mathrm{OH})_{6} \mathrm{Cl}_{2}$. For $x=1$ (herbertsmithite) the GDEx nanoparticles demonstrated a quasi-QSL behavior, whereas for $x=$ $0.3(0.3<x<1$ for paratacamite) and $x=0$ (clinoatacamite) a spin-glass behavior was evidenced. Finally, our discovery not only confirms redox reactions as the driving force to produce spin transition nanoparticles, but also proves a simple way to switch between these magnetic ground states within an electrochemical system, paving the way to further explore its reversibility and overarching implications.
\end{abstract}

Received 20th November 2019 Accepted 24th January 2020

DOI: $10.1039 /$ c9nr09884d rsc.li/nanoscale quantum computing devices (e.g., for storage and memory purposes), and in quantum communications. ${ }^{1,4}$

The copper ions in herbertsmithite are arranged in triangular grids known as kagomé lattices, wherein the spins are uncoupled. ${ }^{5}$ Each spin tends to be anti-parallel to its neighbors, but the geometric arrangement of the sites where the spins sit makes an ordered alignment impossible. So, the spins collapse into a fluctuating state. ${ }^{3,5,6}$ This non-trivial and disordered arrangement, results in magnetically-frustrated materials due to the low spin of the copper ions $(S=1 / 2)$. The entangled interactions continue to fluctuate, even at the lowest temperature of absolute zero. ${ }^{7,8}$ In such condition, the spins in other magnetic states would be already frozen, but in the quantum state, spins are never locked into a particular configuration. ${ }^{6}$ Compounds featuring such lattices are predicted to show no long-range magnetic order due to competing for antiferromagnetic interactions between nearest-neighbor spin centers, ${ }^{2,4-7,9-11}$ thus being also candidates for quantum spin transitions.

Before these materials can be effectively integrated into spintronic technologies, the competitive synthesis of herbertsmithite remains a significant challenge. A major synthesis problem is the production of sizeable amounts at relevant rates, with controllable physicochemical features. Moreover, 
envisioning small-scale applications, its synthesis at the nanoscale has not been reported. Thus, it is uncertain if its spinliquid properties are preserved at such scale. This is also the case for other spin-liquid materials, as well as other spin-transition materials, such as spin-glasses.

The first method reported for synthesizing crystalline $\mathrm{Zn}_{x} \mathrm{Cu}_{4-x}(\mathrm{OH})_{6} \mathrm{Cl}_{2}$ (wherein $x=1$ for herbertsmithite, and $x=0$ and $0.3<x<1$ for its polymorphs, clinoatacamite and paratacamite, respectively) was issued in 2012 (herbertsmithite was originally found in nature only in 2004). ${ }^{6}$ Herbertsmithite and its polymorphs are typically synthesized by hydrothermal, or solvothermal methods (e.g., $458 \mathrm{~K}-473 \mathrm{~K}$ ). Related cuprate compounds of the form $\mathrm{MCu}_{3}(\mathrm{OH})_{6} \mathrm{Cl}_{2}$ with divalent cations (i.e., $\mathrm{M}=\mathrm{Mg}^{2+}, \mathrm{Co}^{2+}, \mathrm{Fe}^{2+}, \mathrm{Mn}^{2+}$, and $\left.\mathrm{Ni}^{2+}\right)^{2}$ and trivalent cations, $\mathrm{MCu}_{3}(\mathrm{OH})_{6} \mathrm{Cl}_{3}\left(\mathrm{M}=\mathrm{Y}^{3+}\right.$ or the lanthanides $\mathrm{Nd}^{3+}$ and $\left.\mathrm{Sm}^{3+}\right),{ }^{12,13}$ have been achieved by unconventional solid-state reactions at higher temperature (e.g., $463 \mathrm{~K}$ ). An ionothermal method, initially designed for the fabrication of new zeolitic solids, has also been described for the preparation of materials with kagomé lattices. ${ }^{14}$ However, as in the case of the methods previously described, the synthesis rates are rather slow (weeks- to months-scale). As an example, it took ten months to grow a $1 \mathrm{~mm}$ monocrystal of herbertsmithite, in a very complicated hydrothermal reactor. ${ }^{9,15}$

Although there is one work presenting the formation of nanoscale clinoatacamite by hydrothermal synthesis at $363 \mathrm{~K}-$ $368 \mathrm{~K}$, there are no equivalent methods available for producing nanoscale herbertsmithite. Furthermore, the study where nanoscale-clinoatacamite is reported does not evidence its magnetic (spin transition) properties, nor the control of other material features, such as crystallite size and stoichiometry, besides requiring the addition of a toxic organic buffer i.e. 2 -( $N$-morpholino) ethanesulfonic acid. ${ }^{16}$

In general, all these methods are limited to meager production rates and have restrained the production of herbertsmithite (and its polymorphs) to limited samples of macroscale materials (i.e., mm-scale). Green synthesis routes are also preferred, but they are also not available thus far. The development of such routes will be a key step forward for innovations, growth, and competitiveness in the digital miniaturization arena-e.g., using quantum technologies in computing and electronics.

It has been experimentally proven for many materials that micro- and nano-scale dimensioned particles can differ in properties $v s$. their macro-scale counterparts. Especially, spin transition materials may display changes in their magnetic properties with size, and the effects at the nanoscale are mainly unknown.

In this work, we present the synthesis of spin transition nanoparticles. Specifically, using copper and zinc chlorides as precursors, our first goal was to achieve the synthesis of $\mathrm{Zn}_{x} \mathrm{Cu}_{4-x}(\mathrm{OH})_{6} \mathrm{Cl}_{2}$ compounds.

By using different concentrations and ratios of $\mathrm{Cu}$ and $\mathrm{Zn}$, different values of $x$ are targeted. The electrochemical method developed, gas-diffusion electrocrystallization (GDEx), results in these materials by the reactive precipitation of intermedi- aries issued from the oxygen reduction reaction (ORR) at a gasdiffusion cathode, with the metal precursors provided. GDEx has been formerly described for the synthesis of iron oxide nanoparticles with a controlled saturation magnetization. ${ }^{17}$ The materials resulting from the present research were investigated by X-ray powder diffraction (XRD), together with quantitative phase analysis (QPA, Rietveld method), infrared spectroscopy (IR) and inductively coupled plasma optical emission spectrometry (ICP-OES). The morphology and size of the nanoparticles were measured using transmission electron microscopy (TEM).

A second goal was to achieve well-controlled magnetic properties linked to the nano-sized $\mathrm{Zn}_{x} \mathrm{Cu}_{4-x}(\mathrm{OH})_{6} \mathrm{Cl}_{2}$ particles. Zero-field-cooled (ZFC) and field-cooled (FC) thermal dependence of magnetization $(M)$ were used to distinguish magnetic phase transitions in these materials down to $2 \mathrm{~K}$. Also, hysteresis loops at $2 \mathrm{~K}$ and $8 \mathrm{kA} \mathrm{m}^{-1}$ (100 Oe) were investigated for the different compositions.

We demonstrate that it is possible to use our novel electrochemical method for the production of spin transition nanoparticles (i.e., herbertsmithite, clinoatacamite, and paratacamite), in a fast, upscalable, atom- and electron-efficient, energy efficient, and environmentally-friendly way, setting a new precedent towards the industrial era of these materials.

\section{Experimental}

\section{Gas-diffusion electrocrystallization reactor}

The electrochemical reactor design described in Prato et al. ${ }^{17}$ was used in this study. As a working electrode, $10 \mathrm{~cm}^{2}$ of VITO CoRE® multilayered carbon-based gas-diffusion cathodes were used to enable the GDEx process. The VITO CoRE® electrodes consisted of a current collector (stainless steel gauze), an active layer (i.e., porous electrically-conducting matrix), and a hydrophobic gas diffusion outer layer (porous PTFE). The composition of the active layer was $20 \%$ PTFE and $80 \%$ active carbon. Norit ${ }^{2}$ SX1G $\left(878 \mathrm{~m}^{2} \mathrm{~g}^{-1}\right.$, Norit Americas Inc., USA) was employed as the active carbon source. The counter electrode (anode) consisted of a $10 \mathrm{~cm}^{2}$ of platinum sheet laser-welded to titanium (Ti) plate current collector. The anode and cathode compartments were separated by an ion-permeable separator (Zirfon® Perl UTP 500, Agfa, Belgium) ${ }^{18}$ A $3 \mathrm{M} \mathrm{KCl}$ saturated $\mathrm{Ag} / \mathrm{AgCl}$ reference electrode ( $+212 \mathrm{mV}$ vs. SHE) (REF 321, Radiometer Analytical, Hach, USA) was inserted in the proximity of the working electrode, via an external connector chamber, filled with $3 \mathrm{M} \mathrm{KCl}$. A long cotton thread (e.g., $30 \mathrm{~cm}$, packed within the external connector chamber) verged the reference and the working electrodes, through a small channel, with the purpose of establishing a microchannel enabling a continuous capillary-suction of the electrolyte. The thread was not treated, since due to its manufacturing process the wax layer that naturally covers cotton fibres is removed, making it more polar and hydrophilic due to exposure of the fibrous structure of cellulose, rich in hydroxyl $\left(\mathrm{OH}^{-}\right)$groups. ${ }^{19}$ 
All potentials here reported are referred versus the standard hydrogen electrode (SHE).

\section{Operation of the gas-diffusion electrocrystallization reactor}

Experiments were conducted on a multichannel potentiostat (VMP-3, Bio-Logic SAS, France). The GDEx process was controlled chronoamperometrically at $-0.15 \mathrm{~V}_{\mathrm{SHE}}$ and room temperature $\left(18^{\circ} \mathrm{C}\right)$ of synthesis. The $\mathrm{pH}$ in the catholyte was monitored using a sensor for continuous measurement of $\mathrm{pH}$ in liquid media (SE555X/1-NMSN pH sensor, Knick, Germany). A $\mathrm{pH}$ data logger was connected to the Bio-Logic potentiostat to simultaneously follow up the $\mathrm{pH} v s$. charge $(Q)$ evolution.

The data logger consisted of a pH transmitter (A1491N-P110-0000, Knick, Germany) with a converter (P15000 H1, Knick, Germany) which transforms the 4-20 mA signal delivered by the transmitter into a $0-10 \mathrm{~V}$ signal.

All experiments were performed in batch mode with recirculation. The catholyte was recirculated at $15 \mathrm{~L} \mathrm{~h}^{-1}$ throughout the cathode compartment, where gas-diffusion electrocrystallization of $\mathrm{Cu}^{2+}$ and $\mathrm{Zn}^{2+}$ occurred. The total liquid volume of catholyte and anolyte was $500 \mathrm{~mL}$, which was continuously stirred in the recirculation reservoir (i.e., a borosilicate glass bottle) using a polygonal, PTFE-coated rotating magnetic stirring bar (i.e., $200 \mathrm{rpm}$ ). The air was fed through the cathodic gas compartment at a flow rate of $200 \mathrm{ml} \mathrm{min}^{-1}$. A mass gas flow meter and controller (GF40 Bronkhorst hi-tech B.V, Netherlands) was set in place. An overpressure of 26 mbar over a water column (see Fig. 1 for a schematic layout) was applied at the gas exhaust.
The GDEx-driven synthesis was carried out using a mixture of $\mathrm{Cu}^{2+}$ and $\mathrm{Zn}^{2+}$ ions as the metal precursors, and $\mathrm{O}_{2}$ (in air) as the oxidant gas through the gas-diffusion cathode. An acidified supporting electrolyte was employed as an anolyte and catholyte, composed by a $\mathrm{NaCl}$ aqueous solution $(0.5 \mathrm{M})$, adjusted at $\mathrm{pH} 3$ by adding $\mathrm{HCl}(1 \mathrm{M})$. In order to tune the formation of stable $\mathrm{Zn}_{x} \mathrm{Cu}_{4-x}(\mathrm{OH})_{6} \mathrm{Cl}_{2}$ products with the desired value for $x$, different $\left[\mathrm{Cu}^{2+}\right]_{0} /\left[\mathrm{Zn}^{2+}\right]_{0}$ ratios were evaluated. $\mathrm{CuCl}_{2} \cdot 2 \mathrm{H}_{2} \mathrm{O}$ 99.999\% (Sigma-Aldrich, Germany) and $\mathrm{ZnCl}_{2}$ 99.999\% (Sigma-Aldrich, Germany) were supplemented, respectively.

Oxygen (in air), provided through the gas chamber of the electrochemical cell (right side chamber, Fig. 1A), was electrochemically reduced at the active porous carbon layer of the gas-diffusion cathode (Fig. 1B). The products of the electrochemical ORR, profusely available at the electrochemical interface, reacted with the metals ions in solution (e.g., $\mathrm{Cu}^{2+}, \mathrm{Zn}^{2+}$ ), which are transported to the hydrophilic porous carbon on the cathode, via the aqueous electrolyte. When these metal ions met the ORR products (or highly reactive intermediaries) supersaturation was reached, resulting in the nucleation of hydroxides or oxides. Additive $\mathrm{OH}^{-}$concentration and supersaturation kept ongoing; thus secondary nucleation and crystal growth proceeded during the transient period of residence of the primary nuclei formed within the cathodic interface. The resulting precipitate progressively striped out, as a result of the flow and polarization conditions. ${ }^{20}$ The solid precipitate was collected in the electrolyte solution and left to sediment under stagnant conditions. Subsequently, the precipitate was washed with deionized water with a $\mathrm{pH}$ set at that of the final synthesis

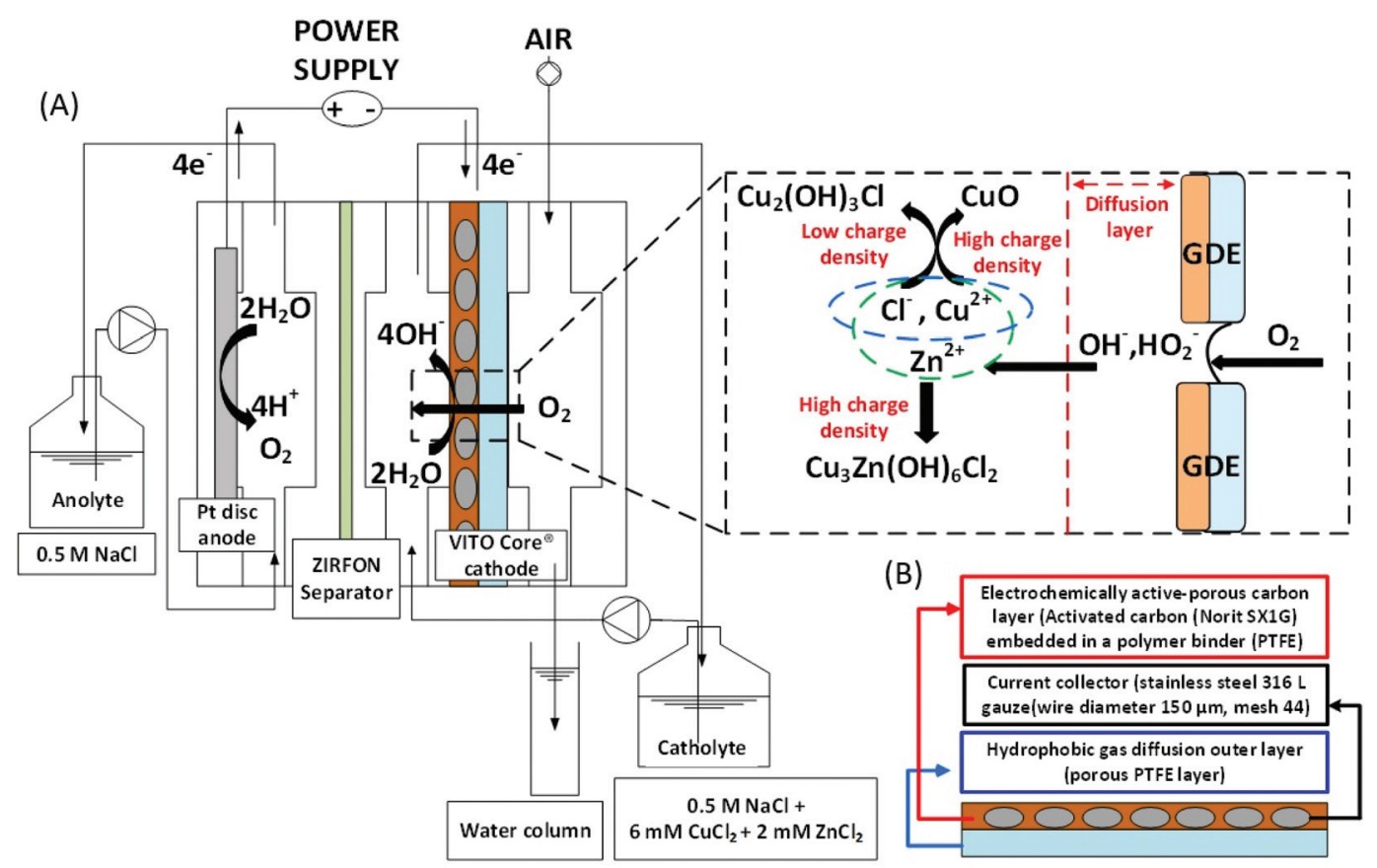

Fig. 1 (A) Gas-diffusion electrocrystallization (GDEx), represented for a batch setup. The potentiostat employed is indicated as a power supply, due to its function. (B) Schematic representation of the parts of the multilayered gas-diffusion electrode employed as cathode. 
solution, re-centrifuged (Jouan CR422, France) at $3000 \mathrm{rpm}$, washed three times, and dried afterwards under a nitrogen atmosphere, resulting in a particulate powder.

\section{Particle size, morphology and structure characterization}

Electronic microscopy. Particle size and morphology were measured by transmission electron microscopy (TEM) using a JEOL JEM 2100FII operated at $200 \mathrm{keV}$. For the observation of the sample in the microscope, the particles were dispersed in butanol, and a drop of the suspension was placed onto a copper grid covered by a carbon film. The mean particle size and distribution were evaluated by counting more than 100 particles using Digital Micrograph ${ }^{\mathrm{TM}}$. After that, data were fitted to a normal distribution to obtain the mean particle size $\left(d_{\mathrm{NP}}\right)$ and standard deviation $(\sigma)$.

X-ray powder diffraction (XRD). The XRD patterns were obtained with a diffractometer (Empyrean, Malvern Panalytical, United Kingdom) using CoK $\alpha$ radiation $(\lambda=$ $1.7928 \AA$ ) with $40 \mathrm{~mA}-45 \mathrm{kV}$ and a finer step size of $0.013^{\circ}$ in the same scan range. Quantitative phase analysis (QPA) by the Rietveld refinement method with the HighScore Plus software (Empyrean, Malvern Panalytical, United Kingdom) was carried out for the quantitative analysis of the phase distribution (\%), using the measured diffraction profile and a calculated profile crystal from the inorganic crystal structure database (ICSD). ${ }^{21,22}$

Stoichiometric analysis. An amount of $50 \mathrm{mg}$ of the precipitate powder sample was transferred into a digestion vessel. Then, $6 \mathrm{~mL}$ of $\mathrm{HCl}$ and $2 \mathrm{~mL}$ of $\mathrm{HNO}_{3}$ were added. The screw cap of the digestion tube was gently turned and placed on a heating block. The temperature was slowly increased to (105 \pm 5) ${ }^{\circ} \mathrm{C}$ and kept for $120 \mathrm{~min}$. The tube was cooled down to room temperature, and water was added to the volume mark. The copper and zinc content in the digested solution was determined by inductively coupled plasma optical emission spectrometry (ICP-OES, Agilent, 5100, USA) in an axial view using ICP-OES equipped with a baffled cyclonic spray chamber and a conical nebulizer. The atomic emission lines of $324.754 \mathrm{~nm}$ and $213.857 \mathrm{~nm}$ were used for copper and zinc, respectively. The metal content in the precipitate sample and the phase percentage calculated by QPA were used to determine the stoichiometric coefficient $x$ on the interlayer site of $\mathrm{Cu}_{4-x} \mathrm{Zn}_{x}(\mathrm{OH})_{6} \mathrm{Cl}_{2}$.

Infrared spectroscopy (IR). IR measurements were performed on a Thermo Scientific, Nicolet iS5 (Waltham, MA, USA), with a diamond plate, and used to distinguish between clinoatacamite and related Zn-polymorphs. The spectra were recorded in the range of $4000-400 \mathrm{~cm}^{-1}$ with a resolution of $2 \mathrm{~cm}^{-1}$.

\section{Magnetic characterization and analysis}

The magnetic characterization was carried out on powder samples in a glycerin capsule and performed in a SQUID magnetometer Quantum Design MPMS-5S, with $5 \mathrm{~T}$ maximum applied field and temperature range from $2 \mathrm{~K}$ to $400 \mathrm{~K}$. The ZFC-FC curves were measured at $8 \mathrm{kA} \mathrm{m}^{-1}$ (100 Oe) from $2 \mathrm{~K}$ to $300 \mathrm{~K}$, with a step of $0.25 \mathrm{~K}$ from $2 \mathrm{~K}$ to $6 \mathrm{~K}, 0.5 \mathrm{~K}$ from $6 \mathrm{~K}$ to $12 \mathrm{~K}$ and more than 1 above $12 \mathrm{~K}$. Before each ZFC measurement, a $3 \mathrm{~T}$ demagnetization field was applied in order to avoid any remanent magnetization in the superconductor coils. The hysteresis loops up to $5 \mathrm{~T}$ were measured at $2 \mathrm{~K}, 3 \mathrm{~K}$, $4 \mathrm{~K}, 6 \mathrm{~K}$, and $15 \mathrm{~K}$.

\section{Results and discussion}

\section{Charge-driven stoichiometric and structural control}

GDEx allows the selective preparation of $\mathrm{Zn}_{x} \mathrm{Cu}_{4-x}(\mathrm{OH})_{6} \mathrm{Cl}_{2}$ materials. By varying the $\left[\mathrm{Cu}^{2+}\right]_{0} /\left[\mathrm{Zn}^{2+}\right]_{0}$ ratio in the GDEx catholyte (wherein $\left[\mathrm{Cu}^{2+}\right]_{0}$ and $\left[\mathrm{Zn}^{2+}\right]_{0}$ correspond to the initial concentration of copper and zinc ionic precursors, respectively), together with a systematic control of the electric charge, the stoichiometric composition of the $\mathrm{Zn}_{x} \mathrm{Cu}_{4-x}(\mathrm{OH})_{6} \mathrm{Cl}_{2}$ products and their structural control, between $\mathrm{Cu}_{2}(\mathrm{OH})_{3} \mathrm{Cl}$ and $\mathrm{CuO}$, can be customized (Fig. 2). For instance, the formation of $\mathrm{Cu}_{2}(\mathrm{OH})_{3} \mathrm{Cl}$ and $\mathrm{CuO}$, for $x=0$, and $\mathrm{Zn}_{x} \mathrm{Cu}_{4-x}(\mathrm{OH})_{6} \mathrm{Cl}_{2}$ within the range of $0.3<x<1$ can be individually targeted, by controlling the operational conditions of GDEx. At $x=0$, the initiallycolorless solution of copper chloride (i.e., at pH 3) turns into an opalescent and greenish-colored dispersion upon reaching $\mathrm{pH} \sim 5$. The color change (see Fig. ESI $1 \dagger$ ) can be attributed to the precipitation of $\mathrm{Cu}_{2}(\mathrm{OH})_{3} \mathrm{Cl}$ (see the green line (a) in Fig. 2), by following reaction (1), in analogy to the mechanism proposed by Engelbrekt et al. ${ }^{16}$

$$
\begin{aligned}
& \mathrm{O}_{2}+4 \mathrm{e}^{-}+2 \mathrm{H}_{2} \mathrm{O}+2 \mathrm{Cu}^{2+}+2 \mathrm{Cl}^{-} \\
& \underset{\text { gas-diffusion cathode }}{\longrightarrow} \mathrm{Cu}_{2}(\mathrm{OH})_{3} \mathrm{Cl}+\mathrm{OH}^{-}+\mathrm{Cl}^{-}
\end{aligned}
$$

A plateau of precipitation can be distinguished at $\mathrm{pH}$ 4.7-5.5, where $1630 \mathrm{C} \mathrm{L}^{-1}$ were consumed from a starting $\mathrm{pH}$ of 3. Upon reaching a $\mathrm{pH}$ of 5.5 , the $\mathrm{Cu}^{2+}$ ions were fully removed from the solution (see Fig. ESI $1 \dagger$ ), followed by a sharp increase of $\mathrm{pH}$, up to 11 -which was reached at a charge consumption of $1875 \mathrm{C} \mathrm{L}^{-1}$. Tenorite $(\mathrm{CuO})$ formed rapidly under alkaline conditions (black line), according to reaction (2).

$$
\mathrm{O}_{2}+4 \mathrm{e}^{-}+2 \mathrm{Cu}^{2+} \underset{\substack{\text { gas-diffusion cathode } \\-0.15 \mathrm{VSHE} ; 1875 \mathrm{C} \mathrm{L}^{-1} ; 18^{\circ} \mathrm{C}}}{\longrightarrow} 2 \mathrm{CuO}
$$

The formation of $\mathrm{Zn}_{x} \mathrm{Cu}_{4-x}(\mathrm{OH})_{6} \mathrm{Cl}_{2}$ with $x=0.3$ can be individually targeted with a combination of low charge consumption (778 $\mathrm{C} \mathrm{L}^{-1}$ ), and a relatively low concentration of $\mathrm{Cu}^{2+}(7.3 \mathrm{mM})$ and $\mathrm{Zn}^{2+}(2.3 \mathrm{mM})$ as the metal precursors as shown in the red line (c) of Fig. 2.

The $\mathrm{pH} v s$. charge evolution of sample $x=1$, represented by the blue line (d) in Fig. 2, is distinct from that with $x=0$, represented by the black line (b) in Fig. 2 .

As zinc ions are substituted onto the interlayer site, a shorter plateau of precipitation is distinguished at $\mathrm{pH}$ 4.7-5.5, wherein $1000 \mathrm{C} \mathrm{L}^{-1}$ had been consumed from a starting $\mathrm{pH}$ of 3. This is attributed to the insertion of chloride ions as part of the chemical structure in the product form, which-concern- 


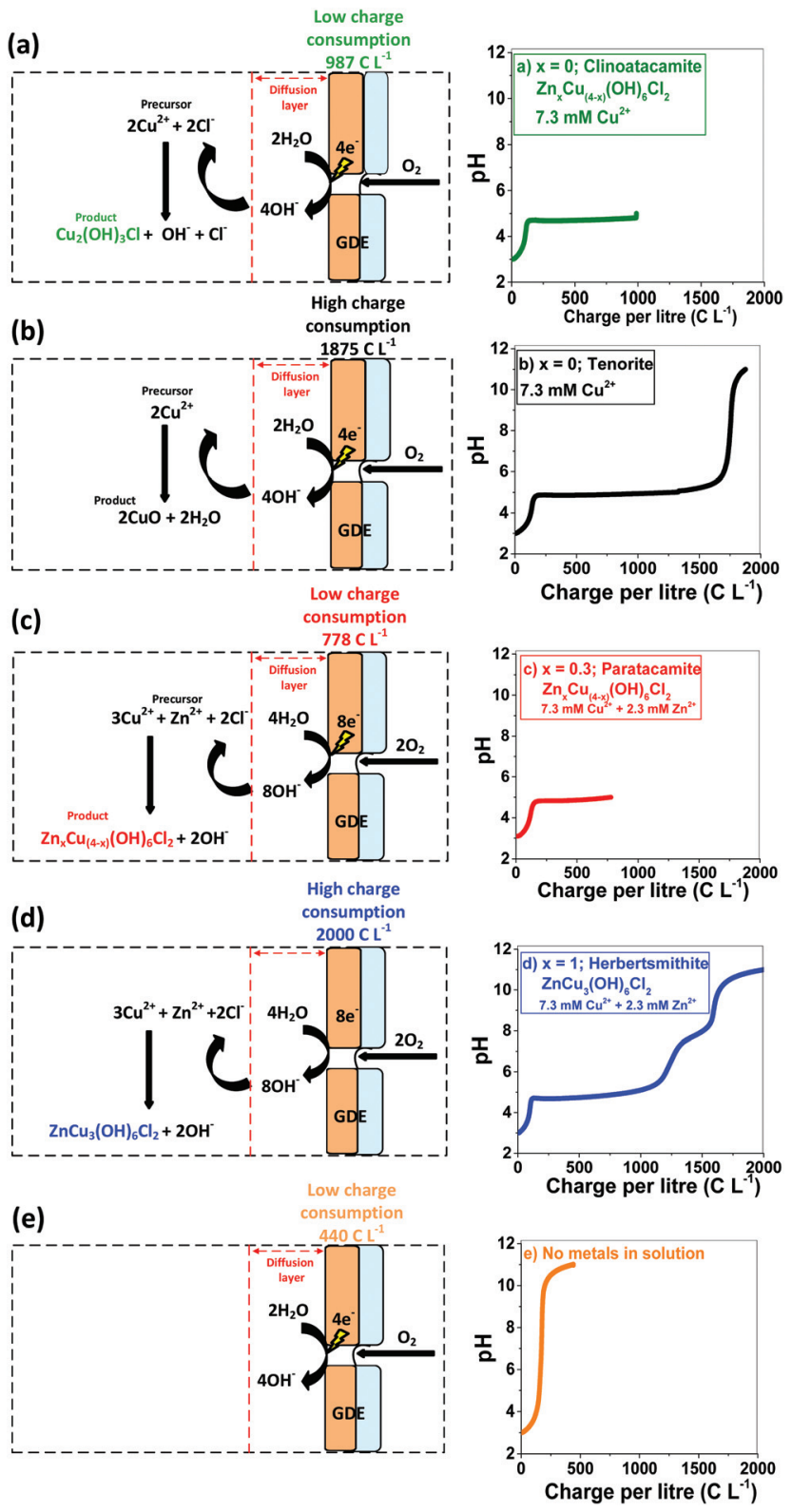

Fig. 2 A suggested mechanism for the synthesis of spin transition nanoparticles. Effect of charge consumption on structural control of (a) $\mathrm{Cu}_{2}(\mathrm{OH})_{3} \mathrm{Cl}$ vs. (b) $\mathrm{CuO}$ and stoichiometric composition control of spin transition compounds $\left(\mathrm{Zn}_{x} \mathrm{Cu}_{4-x}(\mathrm{OH})_{6} \mathrm{Cl}_{2}\right)$ for (c) $x=0.3$ (paratacamite) and (d) $x=1$ (herbertsmithite). (e) The control experiment without metals in solution.

ing $\mathrm{CuO}$ implies a reduced consumption of hydroxide ions, as apparent from comparing reaction (2) vs. reaction (3).

$$
\begin{aligned}
& 2 \mathrm{O}_{2}+8 \mathrm{e}^{-}+4 \mathrm{H}_{2} \mathrm{O}+3 \mathrm{Cu}^{2+}+\mathrm{Zn}^{2+}+2 \mathrm{Cl}^{-} \\
& \text {gas-diffusion cathode } \\
& \mathrm{ZnCu}_{3}(\mathrm{OH})_{6} \mathrm{Cl}_{2}+2 \mathrm{OH}^{-} \\
& -0.15 \text { V SHE; } 2000 \mathrm{C} \mathrm{L}^{-1} ; 18^{\circ} \mathrm{C}
\end{aligned}
$$

The extent of copper and zinc removal from the liquid phase is shown in Fig. ESI $2 . \dagger$ At a higher $\mathrm{Cu}^{2+}$ concentration of $574 \mathrm{mg} \mathrm{L}^{-1}$ and a $\mathrm{Zn}^{2+}$ concentration of $91 \mathrm{mg} \mathrm{L}^{-1}, 100 \%$ of
$\mathrm{Cu}^{2+}$ and $53 \%$ of $\mathrm{Zn}$ ions are removed from the liquid phase at a charge consumption of $2460 \mathrm{C} \mathrm{L}^{-1}$, while $300 \mathrm{mg} \mathrm{L}^{-1} \mathrm{of} \mathrm{Cu}^{2+}$ and $106 \mathrm{mg} \mathrm{L}^{-1}$ achieved $100 \%$ of $\mathrm{Cu}^{2+}$ and $44 \%$ removal of $\mathrm{Zn}$ ions at a charge consumption of $1810 \mathrm{C} \mathrm{L}^{-1}$.

The orange line in Fig. 2 was obtained, as a control experiment without metals in solution. The charge needed to raise the $\mathrm{pH}$ from 3 to 11 was $440 \mathrm{C} \mathrm{L}^{-1}$. The generation of peroxides and free radicals are transient intermediaries, formed together with $\mathrm{OH}^{-}$ions-as per the established mechanism of $\mathrm{O}_{2}$ reduction at non-catalyzed carbon electrodes. ${ }^{23,24}$ After oxygen diffuses to the electrocatalytic surface (i.e., activated carbon) of the gas diffusion electrode (GDE), $\mathrm{O}_{2}$ is reduced (see Fig. 2e). The imposed cathodic polarization conditions (e.g., $-0.15 \mathrm{~V}_{\mathrm{SHE}}$ ) drive this electrolysis mainly to $\mathrm{OH}^{-}$ions via a 4 electron $\left(4 \mathrm{e}^{-}\right)$transfer (eqn (4)), as described in reactions proposed by Šljukić et al. ${ }^{23}$

$$
\mathrm{O}_{2(\mathrm{~g})}+4 \mathrm{e}^{-}+2 \mathrm{H}_{2} \mathrm{O}_{(\mathrm{l})} \underset{\substack{\text { gas-diffusion cathode } \\-0.15 \mathrm{VSHE} ; 440 \mathrm{C} \mathrm{L}^{-1} ; 18^{\circ} \mathrm{C}}}{\longrightarrow} 4 \mathrm{OH}_{(\mathrm{aq})}^{-}
$$

From the charge consumed, it is estimated that a profuse amount of $\mathrm{OH}^{-}$was produced (e.g., $>1300 \mathrm{~mol} \mathrm{~m}^{-3}$ ) resulting from the oxygen reduction reaction, from early stages of the GDEx process. ${ }^{20}$ This would immediately result in a pH of 14 within the porosity of the gas-diffusion cathode,${ }^{24}$ facilitating the onset for hydroxide supersaturation and hence for reactive precipitation (i.e., crystallization) at the electrochemical interface.

\section{Spin transition nanoparticles characterization}

The morphologies of the $\mathrm{Zn}_{x} \mathrm{Cu}_{4-x}(\mathrm{OH})_{6} \mathrm{Cl}_{2}$ particles made by GDEx, at different charge consumption extents, in which $x=0$ for clinoatacamite and $0.3<x<1$ for paratacamite and $x=1$ for herbertsmithite, are shown in Fig. 3(a.2, c2, d2). The experimental evidence for $x=0$, rendered (a2, a3) clinoatacamite $\left(\mathrm{Cu}_{2}(\mathrm{OH})_{3} \mathrm{Cl}\right)$, which was produced as a mixture of faceted nanocrystals and large spiky nanowhiskers $(16 \pm$ $0.4 \mathrm{~nm}$ ), when using a charge consumption of $987 \mathrm{C} \mathrm{L}^{-1}$, while only tenorite (CuO) microwhiskers of $1.5 \mu \mathrm{m}(\mathrm{b} 2, \mathrm{~b} 3)$, with needle-structures, were found at a high charge consumption of $1876 \mathrm{C} \mathrm{L}^{-1}$. This finding is consistent with that of Engelbrekt et al., ${ }^{16}$ who demonstrated differences in the morphology of $\mathrm{CuO}$ microparticles concerning $\mathrm{Cu}_{2}(\mathrm{OH})_{3} \mathrm{Cl}$ nanoparticles, which depended strongly on the reaction conditions by $\mathrm{pH}^{-}$ controlled precipitation. Conversely, by adding the copper and zinc precursors in an adequate ratio, the formation of highly crystalline nanoparticles with sizes that seemingly correspond to single crystals of $\mathrm{Zn}_{x} \mathrm{Cu}_{4-x}(\mathrm{OH})_{6} \mathrm{Cl}_{2}$, is achieved. For samples with a stoichiometric coefficient of $x=0.3$ (c2, c3), the nanocrystals size was $(14 \pm 0.2 \mathrm{~nm})$, obtained with a charge consumption of $778 \mathrm{C} \mathrm{L}^{-1}$. When the stoichiometric coefficient was $x=1(\mathrm{~d} 2, \mathrm{~d} 3)$, the nanocrystals size was $10 \pm 0.1 \mathrm{~nm}$, with a charge consumption of $2000 \mathrm{C} \mathrm{L}^{-1}$.

The frequency of the spin transition nanoparticles sizes and the corresponding normal distribution fits are shown in Fig. ESI 3. $\dagger$ The addition of $\mathrm{Zn}^{2+}$ had a significant effect on the 

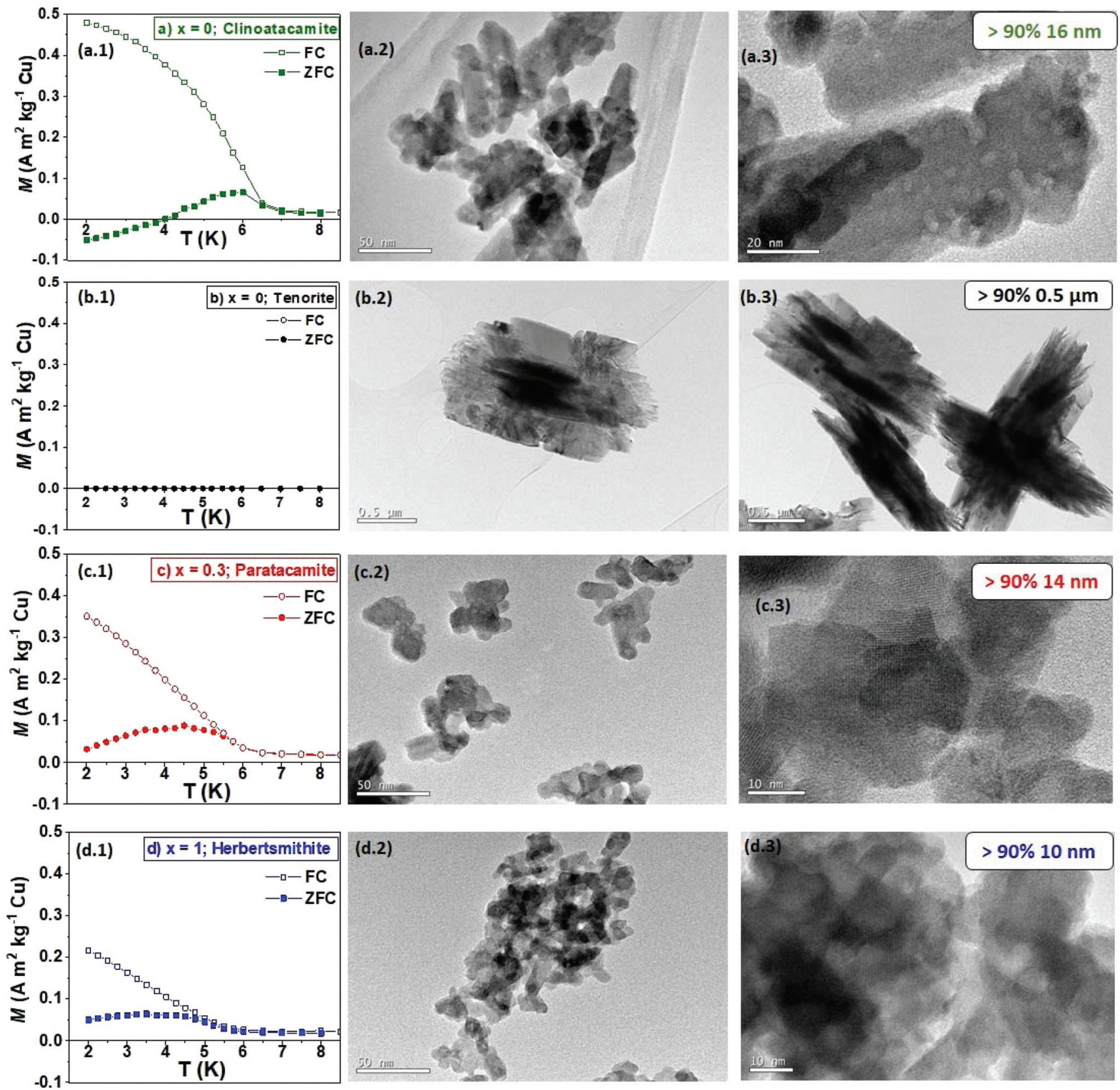

Fig. 3 Temperature dependence of mass magnetization $(M)$ at $8 \mathrm{kA} \mathrm{m}{ }^{-1}(100 \mathrm{Oe})$ for $\mathrm{Zn}_{x} \mathrm{Cu}_{4-x}(\mathrm{OH})_{6} \mathrm{Cl}_{2}$ and $\mathrm{CuO}$ as measured under $\mathrm{ZFC}-\mathrm{FC}$ conditions; (a1-a2) for clinoatacamite; (b1-b2) for tenorite; (c1-c2) for paratacamite and (d1-d2) for herbertsmithite. TEM imaging for $\mathrm{Cu}_{4-x} \mathrm{Zn}_{x}$ $(\mathrm{OH})_{6} \mathrm{Cl}_{2}$ products made by GDEx using $6 \mathrm{mM} \mathrm{Cu}^{2+}$ and $2 \mathrm{mM} \mathrm{Zn}^{2+}$ as precursors.

particle size and polydispersity degree. When the content of zinc was increased from $x=0.3$ to $x=1$, particle sizes reduced from 14 to $10 \mathrm{~nm}$, even at higher alkaline $\mathrm{pH}$ (i.e., 11). The absence of $\mathrm{Zn}$ in the structure, under alkaline conditions, allows the rapid decomposition of $\mathrm{Cu}_{2}(\mathrm{OH})_{3} \mathrm{Cl}$ to $\mathrm{CuO}$ microwhiskers of $1.5 \mu \mathrm{m}$ with needle-structures.

The synthesis of particles at the nanoscale requires very specific supersaturation conditions, such as (1) short nucleation and growth periods, (2) at high rates, and (3) avoiding their immediate agglomeration. ${ }^{25}$ Correspondingly, the synthesis of spin transition nanoparticles by GDEx, is relies on these features, provided by the nature of the process and reagents employed, combined with the following aspects. The flowing conditions impose only a transient contact of metal ion precursors with the reactive species at the saturated electrochemical interface-rendering transient nucleation conditions.

The possibilities of growth are feeble, as encountering other metal ions is restricted by their high dilution. The rate of 
interfacial processes typically scales with available surface area (i.e., surface active sites) which is provided by the highlyporous GDE (i.e., $>800 \mathrm{~m}^{2} \mathrm{~g}^{-1}$ ), facilitating a high rate of production of $\mathrm{HO}_{2}{ }^{-}, \mathrm{OH}^{-}$and their radicals, which quickly react with the metal ion precursors available at the interface.

Notably, the synthesis of $\mathrm{ZnCu}_{3}(\mathrm{OH})_{6} \mathrm{Cl}_{2}$ is fast under the operational conditions here employed, with rates approaching $40 \mathrm{mg} \mathrm{min}^{-1}$. The process is highly reproducible, and it involves mild synthetic conditions (e.g., $291 \mathrm{~K}$ and atmospheric pressure), in contrast to all previous options reported thus far, such as hydrothermal or solvothermal methods (e.g., $\sim 458-473 \mathrm{~K}){ }^{6,15}$

The XRD patterns and IR spectra of 4 representative samples are shown in Fig. 4. The diffraction patterns of Fig. 5A are indexed with the following compounds; $\mathrm{Zn}_{0.25} \mathrm{Cu}_{3.75}(\mathrm{OH})_{6} \mathrm{Cl}_{2}$ (ICSD-no. 192076), $\mathrm{Zn}_{0.85} \mathrm{Cu}_{3.15}(\mathrm{OH})_{6} \mathrm{Cl}_{2}$ (ICSD-no. 424325), $\mathrm{ZnO}$ (ICSD-no. 26170), $\mathrm{Cu}_{2}(\mathrm{OH})_{3} \mathrm{Cl}$ (ICSD-no. 64956) and CuO (ICSDno. 67850).

Table $\mathrm{S} 1 \uparrow$ compares the results obtained from quantitative phase analysis (QPA) by Rietveld refinement method and ICP-OES of powder samples. The synthesis of $\mathrm{Zn}_{x} \mathrm{Cu}_{4-x}(\mathrm{OH})_{6} \mathrm{Cl}_{2}$ compounds using less than $1000 \mathrm{C} \mathrm{L}^{-1}$, resulted in a product with stoichiometric coefficient $x=0.3$ and the lowest amount of impurities, such as $\mathrm{ZnO}$ and $\mathrm{Cu}(\mathrm{OH})_{2}$ (Table $\left.\mathrm{S} 1 \dagger\right)$. At higher charge consumption $\left(2000 \mathrm{C} \mathrm{L}^{-1}\right)$, the synthesis of compounds with higher $\mathrm{Zn}$ content $(x=1)$ is differentiated, but a lower purity is obtained, due to the final pH of synthesis of 11 (see Fig. 2 and duplicate experiment data (d1, d2) in Table S1†).

The XRD traces of $\mathrm{Cu}_{2}(\mathrm{OH})_{3} \mathrm{Cl}$ and $\mathrm{Zn}_{x} \mathrm{Cu}_{4-x}(\mathrm{OH})_{6} \mathrm{Cl}_{2}$ are indistinguishable by X-ray analysis (see Fig. $4 \mathrm{~A}(\mathrm{a}) v s$. A (c)) due to the difficulty to differentiate $\mathrm{Cu}$ and $\mathrm{Zn}$. The crystal structure of $\mathrm{Cu}_{2}(\mathrm{OH})_{3} \mathrm{Cl}$ has been determined by several authors, ${ }^{10,16,26}$ which reported that pure $\mathrm{Cu}_{2}(\mathrm{OH})_{3} \mathrm{Cl}$ occurs in the form of three different polymorphs: atacamite, clinoatacamite, and paratacamite. While the first two polymorphs constitute the thermodynamically-stable phase of $\mathrm{Cu}_{2}(\mathrm{OH})_{3} \mathrm{Cl}$ at ambient temperatures (orthorhombic and monoclinic structure type), paratacamite (rhombohedral structure) has to be stabilized by partial substitution of $\mathrm{Zn}$ or $\mathrm{Ni}$ for $\mathrm{Cu}^{26,27}$ According to the experimental work of Malcherek and Schlüter, ${ }^{26}$ the XRD diffraction pattern of $\mathrm{Zn}_{x} \mathrm{Cu}_{4-x}(\mathrm{OH})_{6} \mathrm{Cl}_{2}$ is weak and therefore easily mistaken by that of $\mathrm{Cu}_{2}(\mathrm{OH})_{3} \mathrm{Cl}$. Differences in the hydroxyl groups of clinoatacamite and herbertsmithite can be used for appropriate identification.

Thus, infrared spectroscopic (IR) studies of $\mathrm{Zn}_{x} \mathrm{Cu}_{4-x}(\mathrm{OH})_{6} \mathrm{Cl}_{2}$ and $\mathrm{CuO}$ were undertaken to overcome the barrier of crystal structure identification encountered with XRD (Fig. 4B). Our data indicate that $\mathrm{Cu}_{2}(\mathrm{OH})_{3} \mathrm{Cl}$ and $\mathrm{ZnCu}_{3}(\mathrm{OH})_{6} \mathrm{Cl}_{2}$ have close lying bands in the hydroxyl stretching region. However, a buried peak at $3400 \mathrm{~cm}^{-1}$ is unique for the $\mathrm{Cu}_{2}(\mathrm{OH})_{3} \mathrm{Cl}$ structure and can be used as a fingerprint for its detection. Also, the slight shifts in the three major bands of the hydroxyl stretching region, allow us to confidently identify our synthesized $\mathrm{Cu}_{2}(\mathrm{OH})_{3} \mathrm{Cl}$ as clinoatacamite. The IR spectrum of the synthesized $\mathrm{CuO}$ compounds supports the phase purity observed by $\mathrm{XRD}$, with no indication of
(A)

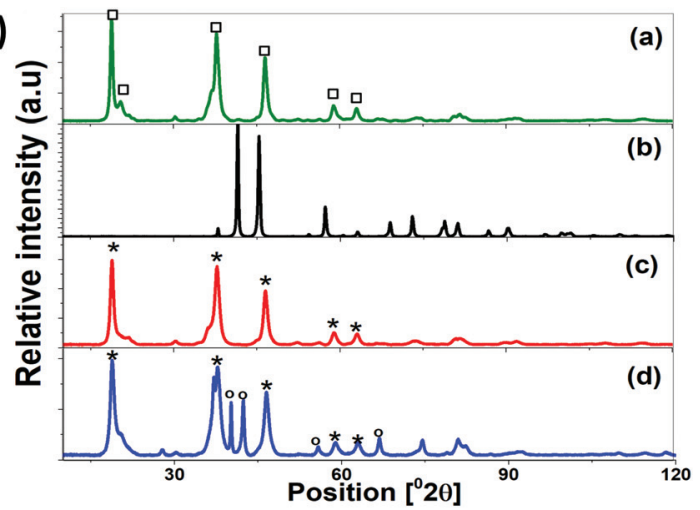

(B)

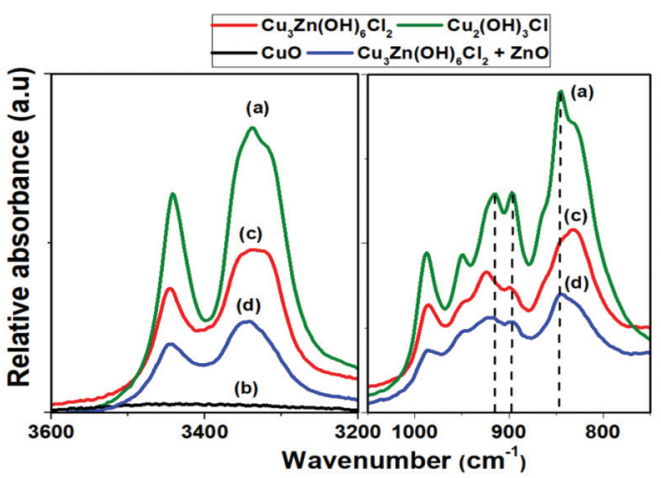

(C)

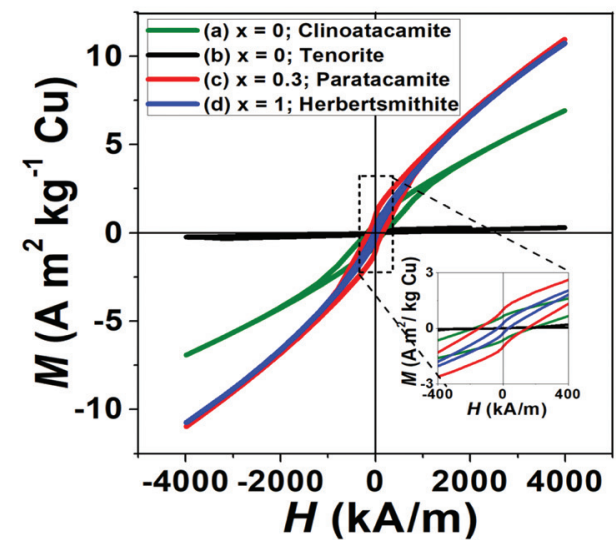

Fig. 4 (A) XRD patterns Co-K $\alpha(\lambda=1.7928 \AA$ ) of solid products obtained using $7.3 \mathrm{mM} \mathrm{Cu}^{2+}$ and $2 \mathrm{mM} \mathrm{Zn}^{2+}$ as metal precursor. From top to bottom: Spin transition compounds with formula $* \mathrm{Zn}_{x} \mathrm{Cu}_{4-x}(\mathrm{OH})_{6} \mathrm{Cl}_{2}$ at $x=0$, XRD patterns of (a) clinoatacamite $\left(\mathrm{Cu}_{2}(\mathrm{OH})_{3} \mathrm{Cl}\right) x=0$ was produced using a charge consumption of $987 \mathrm{C} \mathrm{L}^{-1}$ (green line), while only (b) copper oxide (CuO) $x=0$, at a charge consumption of $1876 \mathrm{C} \mathrm{L}^{-1}$ (black line). (c) Paratacamite $x=0.3$ (red line); (d) herbertsmithite $x=1+$ impurity of zincite (OZnO) (blue line). The asterisk and circular markers show the most prominent peak positions of $\mathrm{Zn}_{x} \mathrm{Cu}_{4-x}(\mathrm{OH})_{6} \mathrm{Cl}_{2}$ and $\mathrm{ZnO}$ phases respectively. The square marker represents the polymorph $\mathrm{Cu}_{2}(\mathrm{OH})_{3} \mathrm{Cl}$. (B) FTIR absorption spectra of the synthesized $\mathrm{Zn}_{x} \mathrm{Cu}_{4-x}(\mathrm{OH})_{6} \mathrm{Cl}_{2}$ with $x=0$ (a) and $\mathrm{Cu}_{2}(\mathrm{OH})_{3} \mathrm{Cl}$ and (b) $\mathrm{CuO}$; (c) $x=0.3$ and (d) $x=1$. The spectra graph is shown in two regions of the hydroxyl stretching $\left(3500-3200 \mathrm{~cm}^{-1}\right)$ and deformation $\left(1000-8000 \mathrm{~cm}^{-1}\right)$. Characteristic frequencies are indicated with vertical dashed lines). (C) $M$ against field over temperature sweep at $2.0 \mathrm{~K}$. Stoichiometric coefficient on the interlayer site ranges of $x$ between 0 to 1 . 


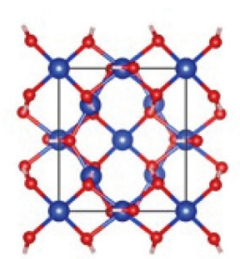

(a1)

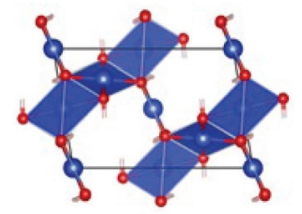

(a2)
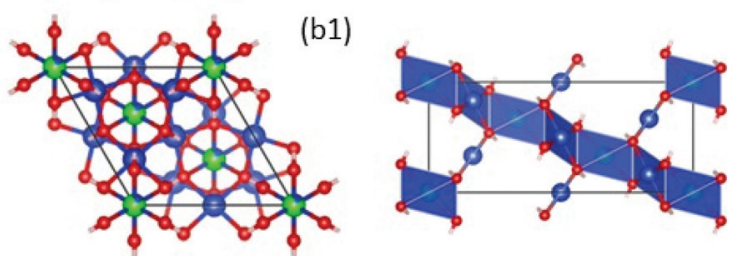

(b2)
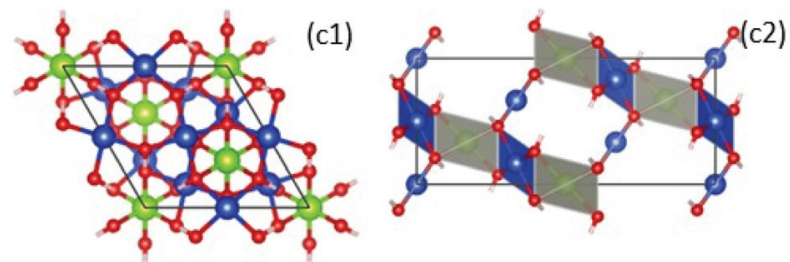

Fig. 5 Left: Crystal structures of compounds with formula $\mathrm{Zn}_{x} \mathrm{Cu}_{4-x}(\mathrm{OH})_{6} \mathrm{Cl}_{2}$ at $x=0$, clinoatacamite (a1), ${ }^{31} \mathrm{Zn}$-paratacamite (b1) ${ }^{10}$ and herbertsmithite $(\mathrm{c} 1)^{9}$ looking down along the hexagonal $c$ axis. Copper atoms are blue, zinc atoms are green, and oxygen (red). Chlorine and hydrogen atoms have been suppressed for clarity to emphasize better that the $\mathrm{CuO}_{4}$ units. Right: A side view of the crystal structure using a polyhedral representation, emphasizing the stacking of the kagome layers due to the coupling of $\mathrm{CuO}_{4}$ planar units by $\mathrm{ZnO}_{6}$ octahedra in herbertsmithite (c2). This figure was made using the Vesta - JP Minerals software, https://jp-minerals.org/vesta/en/, retrieving the XRD data indexed with the following compounds: $\mathrm{Zn}_{0.25} \mathrm{Cu}_{3.75}(\mathrm{OH})_{6} \mathrm{Cl}_{2}$ (ICSD-no. 192076), $\mathrm{Zn}_{0.85} \mathrm{Cu}_{3.15}(\mathrm{OH})_{6} \mathrm{Cl}_{2}$ (ICSD-no. 424325), $\mathrm{Cu}_{2}(\mathrm{OH})_{3} \mathrm{Cl}$ (ICSD-no. 64956), which correspond to the theoretical charts closest to the stoichiometries we achieved experimentally (i.e., see Rietveld analysis in Table S1†).

$\mathrm{Cu}_{2}(\mathrm{OH})_{3} \mathrm{Cl}$, and the stability of $\mathrm{ZnCu}_{3}(\mathrm{OH})_{6} \mathrm{Cl}_{2}$. Similar observations are reported using Raman spectroscopy and IR. ${ }^{16,28}$

\section{Magnetic properties of spin transition nanoparticles}

The thermal and field dependence of magnetization $(M)$ over a temperature sweep down to $2.0 \mathrm{~K}$ are also reported in Fig. 3 (a1, b1, c1 and d1) and 4C. The ZFC and FC thermal dependence of magnetization provides information about the magnetic properties of the spin transition nanoparticles at $8 \mathrm{kA} \mathrm{m}^{-1}$ (100 Oe) (see Fig. 3(a1, c1 and d1)). Tenorite (b1) is an antiferromagnetic semiconductor with Néel temperature $\left(T_{\mathrm{N}}\right)$ of about $230 \mathrm{~K}$ (Fig. ESI $4 \dagger$ ). The ZFC-FC curves and hysteresis loops (Fig. 4C) are typical for $\mathrm{CuO}$ samples. ${ }^{29}$

On the contrary, on cooling and below $T \sim 8 \mathrm{~K}$, the spin transition nanoparticles with formula $\mathrm{Zn}_{x} \mathrm{Cu}_{4-x}(\mathrm{OH})_{6} \mathrm{Cl}_{2}$ showed a transition, which also involves a strong antiferromagnetic (AFM) coupling down to $2 \mathrm{~K}$, especially for clinoatacamite with $x=0$. The strong AFM coupling of $\mathrm{Cu}$ atoms in the triangular lattice makes that the magnetic moments align against the applied field, giving as a result the negative magnetization reversal at low temperatures, especially in clinoataca- mite (a.1). As the temperature increases, the small ferromagnetic (FM) contribution coming from the frustrated geometrical surface becomes to dominate. This effect has been observed in different systems (see "the phenomenon of negative magnetization and its implications") $)^{30}$ and a similar behavior has been reported in $\mathrm{Cu}_{2}(\mathrm{OH})_{3} \mathrm{Cl}^{31,32}$

The negative magnetization shown for clinoatacamite allows us to differentiate between Zn-paratacamite compounds. The high magnetization value at FC in the clinoatacamite also confirms the coupling between a weak FM and a strong AFM interaction. These results are consistent with those of Colman et al., ${ }^{2}$ who indicated the presence of a small amount of ferromagnetic impurities.

The introduction of non-magnetic $\mathrm{Zn}$ in the pyrochlores lattice produces changes in the crystalline structure (from monoclinic to rhombohedral) and the replacement of $\mathrm{Cu}^{2+}$ by non-magnetic $\mathrm{Zn}^{2+}$ weakens the AFM coupling and finally leads to a system of uncoupled spin, as can be seen from ZFCFC curves for $x=0,0.3$ and 1 .

Fig. 5 shows the crystal structure of $\mathrm{Zn}_{x} \mathrm{Cu}_{4-x}(\mathrm{OH})_{6} \mathrm{Cl}_{2}$ compounds, where clinoatacamite $(x=0)$ is a 3D distorted pyrochlore lattice antiferromagnet (a1; a2). The $\mathrm{Zn}^{2+}$ ions (green atoms) can be incorporated into the monoclinic clinoatacamite and converted to a rhombohedral structure with undistorted kagome layers forming a 3D framework structure. ${ }^{5,11}$

The presence of $\mathrm{Zn}^{2+}$ ions in paratacamite (b1; b2) and herbertsmithite $(\mathrm{c} 1 ; \mathrm{c} 2)$ decrease the ordering temperature from $6.5 \mathrm{~K}$ to $4.5 \mathrm{~K}$, which is an indication of spin frustration.

Herbertsmithite $(x=1)$ is proposed as an ideal 2D kagome with $S=1 / 2$, and no long-range magnetic ordering is observed down to $50 \mathrm{mK}$.

Nanoparticles with a stoichiometric coefficient of $x=1$ showed less long-range antiferromagnetic (AFM) ordering or spin freezing than paratacamite nanoparticles $(x=0.3)$. On the contrary, the higher $T_{\mathrm{N}}=6.5 \mathrm{~K}$ of $\mathrm{Cu}_{2}(\mathrm{OH})_{3} \mathrm{Cl}$ with $x=0$ compared to the $T_{\mathrm{N}}=4.5 \mathrm{~K}$ of compounds with $x=1$ supports the stronger AFM coupling of the former; besides, the huge magnetization under FC of samples with $x=0$ confirms the presence of spin glass due to spin frustration of the magnetic moments at the surface.

Magnetization against field over temperature sweep at $2.0 \mathrm{~K}$ was recorded to determine the nature of the magnetic component (Fig. 4C). The hysteresis loops at $2.0 \mathrm{~K}$ of $\mathrm{Cu}_{2}(\mathrm{OH})_{3} \mathrm{Cl}$ shows a kick at low fields confirming the presence of two magnetic phases, one FM and the other AFM (the majority one). The high coercive field $\left(H_{\mathrm{c}}=2500 \mathrm{Oe}=200 \mathrm{kA} \mathrm{m}^{-1}\right)$ indicates also that the $\mathrm{Cu}_{2}(\mathrm{OH})_{3} \mathrm{Cl}$ is a strong AFM.

Compounds with stoichiometry of $\mathrm{Zn}_{x} \mathrm{Cu}_{4-x}(\mathrm{OH})_{6} \mathrm{Cl}_{2}$ showed a paramagnetic-like behavior above the transition temperature and different magnetic couplings at low temperatures (see duplicate experiments in ESI $5 \dagger$ ), where $\mathrm{Cu}_{2}(\mathrm{OH})_{3} \mathrm{Cl}$ developed a stronger magnetic coupling than compounds with $x=1$. The AFM behavior is weakened by the introduction of non-magnetic $\mathrm{Zn}^{2+}$, indicating the formation of spin-spin correlations; which is a common feature of quantum kagomé systems. ${ }^{2-4,6,13,33}$ 
The less ordering temperature in herbertsmithite is a clear indication of spin frustration, which inhibits the tendency of a spin to order under cooling conditions. However, the Néel temperature has not been suppressed as described in the synthesis of a single crystal of herbertsmithite. ${ }^{3}$

This result may be explained by the fact that below a critical size, magnetic particles become single domain in contrast with the usual multidomain structure of microcrystalline samples, which can exhibit unique phenomena such as unusual coercivities, ${ }^{34}$ quantum tunneling of the magnetization, ${ }^{35,36}$ and superparamagnetism. ${ }^{37,38}$ Another possible explanation for this is that the size reduction of herbertsmithite could affect the novel magnetic properties, due to the small volume or the high surface/volume ratio (spin canting effect), ${ }^{39,40}$ a phenomenon through which spins show a lack of full alignment at the surface. For example, Martínez et $a .^{41}$ found a low-temperature surface spin-glass layer in $\mathrm{Fe}_{2} \mathrm{O}_{3}$ magnetic nanoparticles with a ferromagnetic core, indicating a magnetic disorder in a well-delimited surface layer of the nanoparticle. Aliyu et $a l^{42}$ also found a low-temperature surface spin-glass layer in $\mathrm{Pr}_{0.5} \mathrm{Ca}_{0.5} \mathrm{MnO}_{3}$ very crystalline nanoparticles with an antiferromagnetic core and a ferromagnetic shell of a single unit cell thickness; the origin of the glassy state is the magnetic frustration of the ferromagnetic order of the shell.

The ferromagnetic component has been recently explained by muon spin rotation ( $\mu \mathrm{SR}$ ) studies, where a weak ferromagnetic moment appears in the paratacamite family, one around $18 \mathrm{~K}$ and the other one around $6 \mathrm{~K}$, and where dynamics persist down to $T=0 .^{8,31}$

However more in-depth investigation is needed to shed light on a spin canting effect in our spin transition nanoparticles. Although $\mathrm{Zn}_{x} \mathrm{Cu}_{4-x}(\mathrm{OH})_{6} \mathrm{Cl}_{2}$ compounds with $x=1$ showed less long-range antiferromagnetic (AFM) ordering than nanocrystals with a stoichiometric coefficient of $x=0.3$ down to $2 \mathrm{~K}$, further research is required to elucidate if spin canting is responsible for the ferromagnetic component observed, which is in turn could increase the long-range antiferromagnetic (AFM) ordering of spin-transition nanoparticles.

\section{Conclusions}

The possibility of synthesizing spin transition nanoparticles using an electrochemical process with high and fast production rates is desirable for many reasons, notably the convenience of significantly reducing the temperature of synthesis and chemicals, providing a green route of synthesis.

The magnetic properties, particle size and rate of the reaction can be precisely tuned (directly or indirectly) by manipulating the charge consumption, as well as the composition of the electrolyte. This process allows the careful preparation of $\mathrm{Cu}_{4-x} \mathrm{Zn}_{x}(\mathrm{OH})_{6} \mathrm{Cl}_{2}$ products. The synthesis is fast, reproducible and it involves mild synthetic conditions, running at $291 \mathrm{~K}$ and atmospheric pressure, in contrast previously reported methods.
We found faceted nanocrystals of around $10.4 \pm 0.1 \mathrm{~nm}$ for $\mathrm{Zn}_{x} \mathrm{Cu}_{4-x}(\mathrm{OH})_{6} \mathrm{Cl}_{2}$ products with stoichiometric coefficient between $x=0.3$ to 1 . At a charge consumption of $987 \mathrm{C} \mathrm{L}^{-1}$, we produced a mixture of faceted nanocrystals and large spiky nanowhiskers of $16.1 \pm 0.4 \mathrm{~nm}$ with a stoichiometric coefficient of $x=0$. Only microwhiskers of $\mathrm{CuO}(1.5 \mu \mathrm{m})$ with needle-structures were found at higher charge consumption of $1876 \mathrm{C} \mathrm{L}^{-1}$.

Magnetic analyses demonstrate that nanoparticles with $x=$ 1 in the formula $\mathrm{Zn}_{x} \mathrm{Cu}_{4-x}(\mathrm{OH})_{6} \mathrm{Cl}_{2}$ showed a small magnetic transition at $T_{\mathrm{N}}=\sim 4.5 \mathrm{~K}$, with less long-range antiferromagnetic (AFM) ordering or spin freezing than nanoparticles with $x=0.3$ down to $2 \mathrm{~K}$.

ZFC-FC thermal dependence of $M$ shows bifurcation during the transition at $T_{\mathrm{N}}=\sim 6 \mathrm{~K}$ in samples of stoichiometric coefficient between 0 and 0.3 , which supports a long-range AFM ordering, spin freezing or spin-glass-behavior.

These results are in accord with recent studies of synthesis of spin transition compounds indicating that the presence of $\mathrm{Zn}$ allows the perfect kagomé distribution of the $\mathrm{Cu}^{2+}$ ions and consequently lead the absence of long-range ordering to the lowest measured temperature.

We finally suggest that the spin liquid behavior is sustained at the nanoscale in compounds of $\mathrm{ZnCu}_{3}(\mathrm{OH})_{6} \mathrm{Cl}_{2}$. Our discovery not only confirms redox reactions as the driving force to produce spin transition nanoparticles, but also proves a simple way to switch between these magnetic ground states within an electrochemical system, paving the way to further explore its reversibility and overarching implications.

\section{Conflicts of interest}

There are no conflicts to declare.

\section{Acknowledgements}

G. Pozo acknowledges the funding from the European Union's Horizon 2020 research and innovation programme MSCA-IF-2017, under grant agreement no. 796320 (MAGDEx: Unmet MAGnetic properties in micro and nano-particles by synthesis through gas diffusion electrocrystallisation, (GDEx).

$\mathrm{X}$. Dominguez-Benetton thanks to VITO's strategic research funds and management for the possibility to conduct this pioneering research. GP, RP, JF, and XDB thank the support from the Flemish SIM MaRes programme, under grant agreement no. 150626 (Get-A-Met project). XDB and JF thanks the funding from the European Union's Horizon 2020 research and innovation programme under grant agreement no. 654100 (CHPM2030 project). This work has been supported by the Ministerio Español de Economía y Competitividad (MINECO) RTI2018-095856-B-C21, and Comunidad de Madrid S2013/ MIT-2850 NANOFRONTMAG projects. We would also like to acknowledge Myriam Mertens for fruitful discussions and her 
support on XRD analysis, as well as Kristof Tirez and Wilfried Brusten for assistance with analytical measurements.

\section{References}

1 L. Balents, Nature, 2010, 464, 199-208.

2 R. H. Colman, A. Sinclair and A. S. Wills, Chem. Mater., 2011, 23, 1811-1817.

3 M. Shores, E. Nytko, B. Bartlett and D. Nocera, J. Am. Chem. Soc., 2005, 127, 13462-13463.

4 R. Colman, C. Ritter and A. Wills, Chem. Mater., 2008, 20, 2005-2007.

5 M. R. Norman, Rev. Mod. Phys., 2016, 88, 1-14.

6 T. Han, J. Helton, S. Chu, A. Prodi, D. Singh, C. Mazzoli, P. Müller, D. Nocera and Y. Lee, Phys. Rev. B: Condens. Matter Mater. Phys., 2011, 83, 100402-100406.

7 J. S. Helton, K. Matan, M. P. Shores, E. A. Nytko, B. M. Bartlett, Y. Yoshida, Y. Takano, A. Suslov, Y. Qiu, J. H. Chung, D. G. Nocera and Y. S. Lee, Phys. Rev. Lett., 2007, 98, 3-6.

8 P. Mendels, F. Bert, M. A. De Vries, A. Olariu, A. Harrison, F. Duc, J. C. Trombe, J. S. Lord, A. Amato and C. Baines, Phys. Rev. Lett., 2007, 98, 1-4.

9 M. P. Shores, E. A. Nytko, B. M. Bartlett and D. G. Nocera, J. Am. Chem. Soc., 2005, 127, 13462-13463.

10 M. D. Welch, M. J. Sciberras, P. A. Williams, P. Leverett, J. Schlüter and T. Malcherek, Phys. Chem. Miner., 2014, 41, 33-48.

11 P. Mendels and F. Bert, J. Phys. Soc. Jpn., 2010, 79, 011001.

12 W. Sun, Y. X. Huang, Y. Pan and J. X. Mi, Dalton Trans., 2017, 46, 9535-9541.

13 W. Sun, Y. X. Huang, S. Nokhrin, Y. Pan and J. X. Mi, J. Mater. Chem. C, 2016, 4, 8772-8777.

14 F. Aidoudi, D. Aldous, R. Goff, A. Slawin, J. Attfield, R. Morris and P. Lightfoot, Nat. Chem., 2011, 3, 801-806.

15 T.-H. Han, J. S. Helton, S. Chu, D. G. Nocera, J. A. Rodriguez-Rivera, C. Broholm and Y. S. Lee, Nature, 2012, 492, 406-410.

16 C. Engelbrekt, P. Malcho, J. Andersen, L. Zhang, K. Ståhl, B. Li, J. Hu and J. Zhang, J. Nanopart. Res., 2014, 16(16), 2562.

17 R. A. Prato, V. Van Vught, S. Eggermont, G. Pozo, P. Marin, J. Fransaer and X. Dominguez-Benetton, Sci. Rep., 2019, 9, 15370.

18 P. Vermeiren, W. Adriansens and R. Leysen, Int. J. Hydrogen Energy, 1996, 21, 679-684.

19 D. Agustini, M. F. Bergamini and L. H. Marcolino-Junior, Lab Chip, 2016, 16, 345-352.

20 X. Dominguez Benetton, Y. Alvarez, C. Porto-Carrero, K. Gijbels and S. Rajamani, US2018/0023201A1, 2018, 40.
21 A. Belsly, M. Helderman, V. L. Karen and P. Ulkch, Acta Crystallogr., Sect. B: Struct. Sci., 2002, 58, 364-369.

22 C. H. Görbitz, Acta Crystallogr., Sect. B: Struct. Sci., Cryst. Eng. Mater., 2016, 72, 167-168.

23 B. Šljukić, C. E. Banks and R. G. Compton, J. Iran. Chem. Soc., 2005, 2, 1-25.

24 H.-H. Yang and R. L. McCreery, J. Electrochem. Soc., 2000, $147,3420$.

25 A. Mersmann and M. Löffelmann, Chem. Eng. Technol., 2000, 23, 11-15.

26 T. Malcherek and J. Schlüter, Acta Crystallogr., Sect. B: Struct. Sci., 2009, 65, 334-341.

27 R. S. W. Braithwaite, K. Mereiter, W. H. Paar and A. M. Clark, Mineral. Mag., 2004, 68, 13.

28 G. Bertolotti, D. Bersani, P. P. Lottici, M. Alesiani, T. Malcherek and J. Schlüter, Anal. Bioanal. Chem., 2012, 402, 1451-1457.

29 D. Gao, Z. Yang, J. Zhang, G. Yang, Z. Zhu, J. Qi, M. Si and D. Xue, AIP Adv. , 2011, 1, 042168.

30 N. Kumar and A. Sundaresan, Solid State Commun., 2010, 150, 1162-1164.

31 X. G. Zheng, T. Kawae, Y. Kashitani, C. S. Li, N. Tateiwa, K. Takeda, H. Yamada, C. N. Xu and Y. Ren, Phys. Rev. B: Condens. Matter Mater. Phys., 2005, 71, 4-7.

32 S. Chu, P. Müller, D. Nocera and Y. Lee, Appl. Phys. Lett., 2011, 98, 1-3.

33 M. Schmidt, F. M. Zimmer and S. G. Magalhaes, Phys. A, 2015, 438, 416-423.

34 E. F. Kneller and F. E. Luborsky, J. Appl. Phys., 1963, 34, 656-658.

35 F. L. Pratt, P. J. Baker, S. J. Blundell, T. Lancaster, S. OhiraKawamura, C. Baines, Y. Shimizu, K. Kanoda, I. Watanabe and G. Saito, Nature, 2011, 471, 612-616.

36 D. Galetti, B. M. Pimentel, C. L. Lima and E. C. Silva, Phys. A, 2009, 388, 1105-1110.

37 A. G. Kolhatkar, A. C. Jamison, D. Litvinov, R. C. Willson and T. R. Lee, Int. J. Mol. Sci., 2013, 14, 15977-16009.

38 F. Arteaga-Cardona, K. Rojas-Rojas, R. Costo, M. A. Mendez-Rojas, A. Hernando and P. De La Presa, J. Alloys Compd., 2016, 663, 636-644.

39 R. Topkaya, O. Akman, S. Kazan, B. Aktaş, Z. Durmus and A. Baykal, J. Nanopart. Res., 2012, 14(1156), 14.

40 A. T. Ngo, P. Bonville and M. P. Pileni, J. Appl. Phys., 2001, 89, 3370-3376.

41 B. Martínez, X. Obradors, L. Balcells, a. Rouanet and C. Monty, Phys. Rev. Lett., 1998, 80, 181-184.

42 H. D. Aliyu, J. M. Alonso, P. de la Presa, W. E. Pottker, B. Ita, M. Garcia-Hernández and A. Hernando, Chem. Mater., 2018, 30, 7138-7145. 